\title{
Coordinated planning in improving power quality considering the use of nonlinear load in radial distribution system
}

\author{
Muhira Dzar Faraby ${ }^{1}$, Ontoseno Penangsang ${ }^{2}$, Rony Seto Wibowo ${ }^{3}$, Andi Fitriati ${ }^{4}$ \\ 1,2,3 Department of Electrical Engineering, Institute Technology of Sepuluh Nopember, Indonesia \\ ${ }^{1,4}$ Department of Mechatronic Engineering, Polytechnic of Bosowa, Indonesia
}

\section{Article Info \\ Article history: \\ Received Sep 4, 2020 \\ Revised Apr 28, 2021 \\ Accepted May 11, 2021}

\section{Keywords:}

Capacitor

Coordinated planning

Distributed generation

Particle swarm optimization

Reconfiguration

\begin{abstract}
Power quality has an important role in the distribution of electrical energy. The use of non-linear load can generate harmonic spread which can reduce the power quality in the radial distribution system. This research is in form of coordinated planning by combining distributed generation placement, capacitor placement and network reconfiguration to simultaneously minimize active power losses, total harmonic distortion (THD), and voltage deviation as an objective function using the particle swarm optimization method. This optimization technique will be tested on two types of networks in the form 33-bus and 69-bus IEEE Standard Test System to show effectiveness of the proposed method. The use of MATLAB programming shows the result of simulation of increasing power quality achieved for all scenario of proposed method.
\end{abstract}

This is an open access article under the CC BY-SA license.

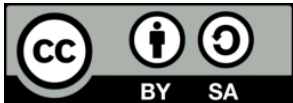

\section{Corresponding Author:}

Ontoseno Penangsang

Department of Electrical Engineering

Institute Technology of Sepuluh Nopember

ITS Highway, Keputih, Sukolilo, Surabaya, 60117, Indonesia

Email: zenno_379@yahoo.com

\section{INTRODUCTION}

The economic and technological improvement followed by increasing the use of electricity is a major challenge that carries complex problems especially in the case of power quality. The smarter distribution system is expected to drive the good power quality in the distribution system. Nowadays, nonlinear load on control devices and power switching apparatus increase rapidly due to the high efficiency and easy operation and control [1]. The harmonic problems are mainly due to the substantial increase of nonlinear load because of technological advances such as the use of power electronic circuit and devices and $\mathrm{AC} / \mathrm{DC}$ transmission links or the control of power system using power electronics or microprocessor controllers. Increase in harmonic spread will result in additional heating losses, shorter insulation lifetime, higher temperature and insulation stress, reduced power factor, and error on measurement [2], [3]. Modern appliances are increasingly adopting power electronic devices faced nowadays due to energy efficiency considerations. This trend has generated the increased harmonic distortion in the power residential distribution system now that harmonic distortion by residential load has apparently become an increasing concern due to the extensive adoption of power electronic-based home appliances [4]. The harmonic source produces a non-sinusoidal current which flaws where each periodic wave is not a sinus form containing harmonic. Reviewing the consequences arising from the distribution of harmonics, harmonic load flow method is used to determine and analyze the spread and magnitude of harmonic in the distribution system [5]-[8]. Backward-forward method for a power flow analysis is applied to obtain a voltage profile on each 
bus and the real power losses at fundamental frequencies, and harmonic load flow is practiced obtaining the distortion voltage profile on each bus and the harmonic losses caused by the use of non-linear loads [9]-[11].

The use and development of small-scale electric power plants integrated into radial distribution systems is a new breakthrough known as distributed generation (DG). The DG operation process is relatively simple, and DG is able to improve power quality and easily obtain environmentally friendly and primary energy sources [12], [13]. The placement of DG can comply with the harmonic limits discussed in [14]-[16]. Harmonic resonance problems have been minimized by the use of the smart DG in distribution systems [17]. The distorted current injected by the DG based renewable source can make a harmonic problem more severe if the placement of DGs is applied with the non-optimal size [18], [19]. The capacitors are reactive power compensators. However, the similar ones can magnify the effect of harmonics of the load due to the existence of resonance with the inductive elements. The effects of capacitor integration on voltage largely depend on their size and placement. However, they can increase or reduce the spread of harmonics in the distribution system [20], [21]. Distribution network reconfiguration is a technique that has been identified as an effectively helpful method for improving the performance of systems by minimizing active power losses, balancing load, improving service, and increasing the voltage profile on each bus in radial distribution systems [22]. Distribution system reconfiguration primarily proposed for the loss minimization has been recently considered an effective solution for many power quality problems in the grids. New reconfiguration solution strategies for the harmonic minimization are proposed [23]. Distributed energy resources (DERs) are some energy sources that can enhance the performance system and can be operated in on and off grid modes. DERs are usually connected at the distribution system due to their power and voltage range. DERs provide an additional opportunity for mitigation of harmonics spreads in distribution systems [24].

The spread of harmonics in distribution systems requires a special attention to the planning and design of distribution system expansion. Inadequate planning and operation can worsen the condition of the system and result in the damage to the equipment due to the spread of harmonics. An intelligent planning is able to maintain and improve the performance summarized in a coordinated planning. Coordinated planning is a planning activity that coordinates several optimization techniques to achieve the stated objective function. Several previous studies on the combination of optimization techniques overcome the spread of harmonics in the distribution system. A combination of network reconfiguration and DG placement uses the branch exchange technique method. Reconfiguration is less effective after DERs are placed, and the combination of optimization techniques had better be simultaneously carried out [22]. Evaluation of network reconfiguration for several types of loads uses the non-iterative harmonic load flow method by forward backward sweep. The reconfiguration result is influenced by the load model in the system tested by IEEE 69bus standard test system. [25]. Capacitor placement and network reconfiguration done simultaneously using the New-PSO, ACO, and HS methods generate a better numerical result better than those done sequentially with multi objective functions such as minimum $\mathrm{P}_{\text {Loss }}$ and $\% \mathrm{THD}_{\mathrm{v}}$ [26]. Optimization of placement of DERs (DG and Capacitor) uses the $\mathrm{BBO}, \mathrm{PSO}, \mathrm{ABC}$, and $\mathrm{DE}$ Method. Investigation of the uses of metaheuristic methods results in different performances tested in the IEEE 33-bus test standard system. The DG placement done with and without capacitors installed in the system significantly influences power quality on each used method. Power factor value consideration on the capacitors impacts the effect of harmonic distortion, and the simultaneous application of two optimization techniques is highly recommended [27] and teaching learning based optimization method needs applying to optimize the power injection of the DERs on the particular places in the distribution system considering nonlinear loads for the power quality improvement [28].

A smarter distribution system is expected to control good power quality to the system. However, this case is a complicated demand to maintain according to the needs and increase the existing load. Especially with the use of semiconductor equipment or the switching process which is increasing rapidly due to high efficiency and ease of operation and control [29]. Coordinated planning in the form of planning activities to coordinate optimization techniques from DG placement, capacitor placement and network reconfiguration on a radial distribution system to produce the best strategy in finding solutions to combinatory optimization problems that have a single or multiple objective function according to the constraints determined by sequentially or simultaneously [30]. The combination of three optimization techniques namely DG placement, Capacitor placement and network reconfiguration using the genetic algorithm method which is summarized in a coordinated plan to maximize optimal power flow that obtains a better result than two techniques [31], [32]. In order to obtain the best benefit regarding power quality considering the harmonic spread, the combination of three optimization techniques is implemented. A few studies have confirmed that the use of artificial intelligence (AI) methods is considered capable of the best solution. Particle swarm optimization (PSO) is one of the AI types considered being able to offer the best solution in solving issues on the optimization technique used [33]. This research will discuss the development of previous research related to the optimization of a combination of three optimization techniques that aim to improve power quality to the distribution of harmonics by considering the use of non-linear loads in a radial distribution system using 
the particle swarm optimization method with a harmonic load flow method by forward backward sweep method.

\section{METHOD}

\subsection{Objective function}

Objective function used to optimize the optimization technique performed in coordinated planning in this study is in the form of a multi objective function, i.e.

1) Minimum active power losses $\left(P_{\text {Loss }}\right)$

The fundamental active power losses component and the harmonic component are defined.

$$
\begin{aligned}
& P_{\text {Loss }}=\sum_{i=1}^{n b} P_{\text {Loss }_{i}}{ }^{(1)}+\sum_{i=1}^{n b} \sum_{h=h_{0}}^{h_{\max }} P_{\text {Loss }_{i}}{ }^{(h)} \\
& f(x)_{1}=\min P_{\text {Loss }}
\end{aligned}
$$

$P_{\text {Loss }} \quad=$ Total active power losses

$P_{\text {Loss }_{i}}{ }^{(1)} \quad=$ Fundamental active power losses

$P_{\text {Loss }_{i}}{ }^{(h)} \quad=$ Harmonic component active power losses

$h_{\max }=$ the maximum harmonic orders

$h_{0} \quad=$ the minimum harmonic orders

2) Minimum total harmonic distortion (THD)

THD of voltage is one of principal indexes of distortion considered by IEEE519-1992 Standard. Reducing THD enhances power quality standards and allows the finding of solution with lower distortion indexes.

$$
\begin{aligned}
& \% V_{T H D, i}=\frac{V_{d, i}}{V_{r m s, i}} * 100 \% \\
& f(x)_{2}=\min \% V_{T H D_{i}}
\end{aligned}
$$

$V_{T H D, i}=$ total harmonic distortion voltage

$V_{d, i}=$ absolute voltage on fundamental frequency

$V_{r m s, i}=$ total rms voltage

3) Minimum voltage deviation $(\Delta V)$

Voltage deviation is defined as a difference between the maximum (swing bus) and other voltage bus on each bus. By reducing voltage deviation, the optimization process can improve the voltage condition in all system nodes and for all the load level.

$$
\begin{gathered}
\Delta V=\left|\frac{V_{i}-V_{1}}{V_{1}}\right| \\
f(x)_{3}=\min \Delta V \\
\Delta V \quad=\text { Voltage deviation } \\
V_{1} \quad=\text { Swing bus voltage } \\
V_{i} \quad=\text { Voltage bus on each bus }
\end{gathered}
$$

The next step is to calculate the objective function. So, the equation of the multi objective function is,

$$
f(x)=a f(x)_{1}+b f(x)_{2}+c f(x)_{3}
$$

where $a, b$, and $c$ are penalty factors that determine the sizing of the priority scale and find the objective function based on statistical information on losses, total harmonic distortion, and voltage deviation. 


\subsection{Constrain}

1) Bus voltage limit

$V_{\min }$ and $V_{\max }$ represent the lower and the upper limits of the voltage at each bus $i$.

$$
V_{\min }(0.95 \mathrm{pu}) \leq V_{\text {rmsi }} \leq V_{\max }(1.05 \mathrm{pu})
$$

2) Total harmonic distortion limit

The THD on each bus of the system should not exceed its maximum permissible value according to IEEE 519-1992 standard.

$$
T H D_{i}(\%) \leq T H D_{\max }
$$

3) Number and sizing of DG

The number of DGs to be placed is 4 and the size are.

$$
\begin{gathered}
0 \mathrm{~kW} \leq P_{D G} \leq 200 \mathrm{~kW} \text { for IEEE } 33 \text {-bus test system } \\
0 \mathrm{~kW} \leq P_{D G} \leq 250 \mathrm{~kW} \text { for IEEE } 69 \text {-bus test system } \\
P_{D G}=\text { Active power injected by DG }
\end{gathered}
$$

4) Number and sizing of capacitor

The number of capacitors to be placed is 4 and the size are.

$$
\begin{aligned}
& 0 k V a r \leq Q_{C a p} \leq 50 \mathrm{kVar} \text { for IEEE } 33 \text {-bus test system } \\
& 0 \mathrm{kVar} \leq Q_{C a p} \leq 100 \mathrm{kVar} \text { for IEEE } 69 \text {-bus test system }
\end{aligned}
$$

$Q_{\text {Cap }}=$ Reactive power injected by capacitor

5) The new distribution network topology remains in a radial condition after activating tie switch and opening sectional switch.

\subsection{Particle swarm optimization (PSO)}

In PSO, each particle that is roaming through the $D$-dimensional problem hyperspace represents the potential solution for a specific problem. For each of $I$ two vectors $X_{i}$ is position vector and $V_{i}$ is velocity vector. In addition, each particle $i$ can memorise its personal best experience ever encountered, represented by personal best position vector $P_{i}$. The position attained by the best particle in the society is represented as $P_{g}$. Mathematically, at iteration $(t+1)$ of the searching process, the $d$ th dimention of particle $i$ 's velocity, $V_{i, d}(t+1)$ and position $X_{i, d}(t+1)$ are updated as follows [34].

$$
\begin{aligned}
& V_{i d}(t+1)=V_{i d}(t)+c_{1} \operatorname{rand}_{1}\left(P_{i d}(t)-X_{i d}(t)\right)+c_{2} \operatorname{rand}_{2}\left(P_{g d}(t)-X_{i d}(t)\right) \\
& X_{i d}(t+1)=X_{i d}(t)+V_{i d}(t+1)
\end{aligned}
$$

$$
\begin{array}{ll}
V_{i d} & =\text { Particle speed } \\
c_{1}, c_{2} & =\text { Coefficient of acceleration } \\
\text { rand }_{1}, \text { rand }_{2} & =\text { Random particle position } \\
P_{i d} & =\text { Local best position } \\
X_{i d} & =\text { Particle position } \\
P_{g d} & =\text { Global best position }
\end{array}
$$

Parameter PSO used is the population=100, iteration=100, $a=0.5, b=0.5, c=0.5, c_{1}=2$ and $c_{2}=2$. The stages of the research carried out is shown in Figure 1. In this study, the sizing $a, b$, and $\mathrm{c}$ is made equivalent in finding multi objective function on the constrain determined. 


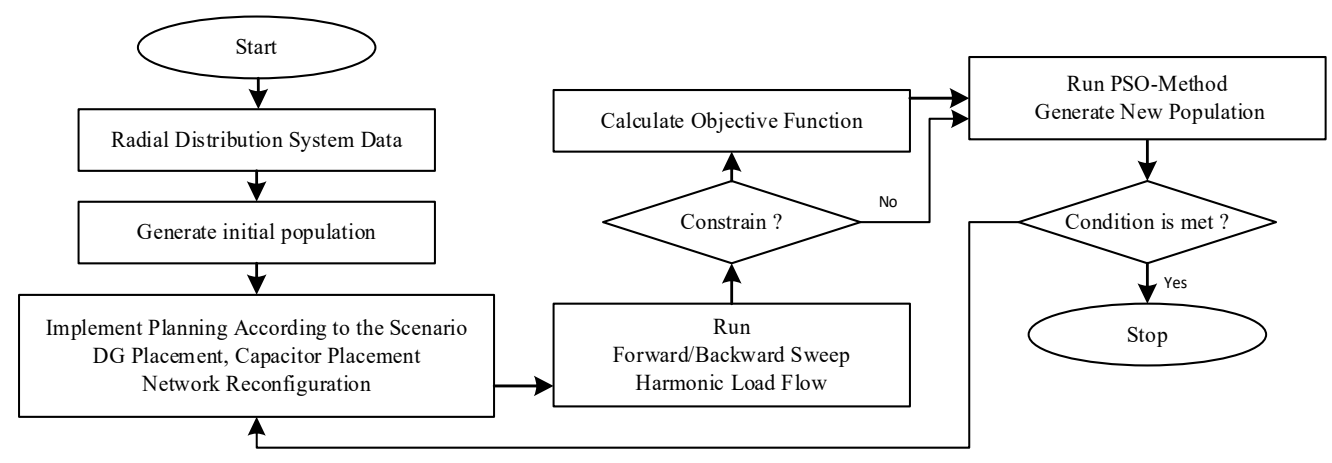

Figure 1. Flowchart of research stages

\subsection{Object data and study case}

\subsubsection{Harmonic source}

The harmonic sources from nonlinear load will be given to load bus which aims to generate the distribution of harmonics in radial distribution system which is shown in Table 1.

Table 1. Injection of harmonic source in load bus [35]

\begin{tabular}{ccc}
\hline Orde & Magnitude $(\%)$ & Angle \\
\hline 5 & 98 & 140 \\
7 & 39.86 & 113 \\
11 & 18.85 & -158 \\
13 & 9.79 & -178 \\
17 & 2.5 & -94 \\
\hline
\end{tabular}

\subsubsection{IEEE 33-bus}

In IEEE 33-bus radial distribution system, the main feeder originates from the substation and passes through different costumer load. There are 32 sectional switches and 5 tie switches that is shown in Figure 2. Harmonic source will be injected on bus 5, 7, 9, 11, 14, 17, 20, 24, 27, 29, 31 and 33. The total peak demand of system is $4.37 \mathrm{MVA}$, and power factor is 0.85 . All data on this system is in per-unit (pu) form where the best values of power and voltage are $100 \mathrm{MVA}$ and $12.66 \mathrm{kV}$.

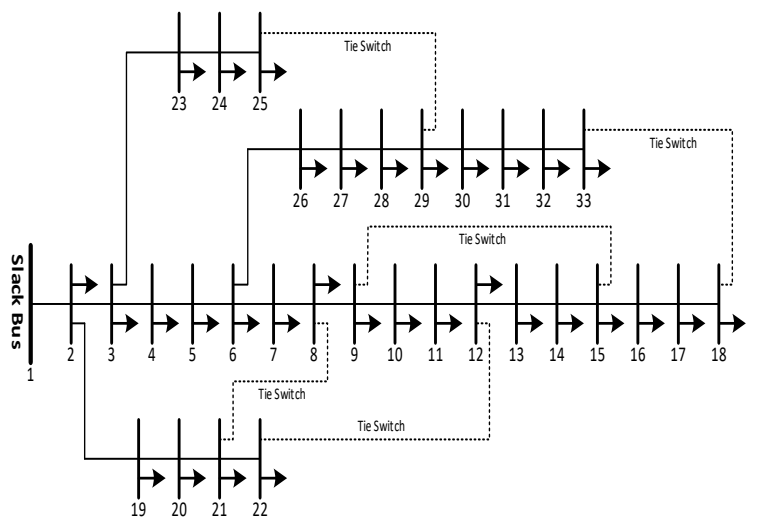

Figure 2. IEEE-33 bus test system

\subsubsection{IEEE 69-bus}

On IEEE-69 bus, there are 47 sectional switches and 5 tie switches that is shown in Figure 3. Harmonic source will be injected on bus $6,9,14,17,22,27,33,37,40,43,49,55,61$, and 69 . On the IEEE 69-bus test system, the total peak demand of system is $4.66 \mathrm{MVA}$, and the power factor is 0.81 . All data on this system are in per-unit $(\mathrm{pu})$ form where the best values of power and voltage are $100 \mathrm{MVA}$ and $12.66 \mathrm{kV}$. 


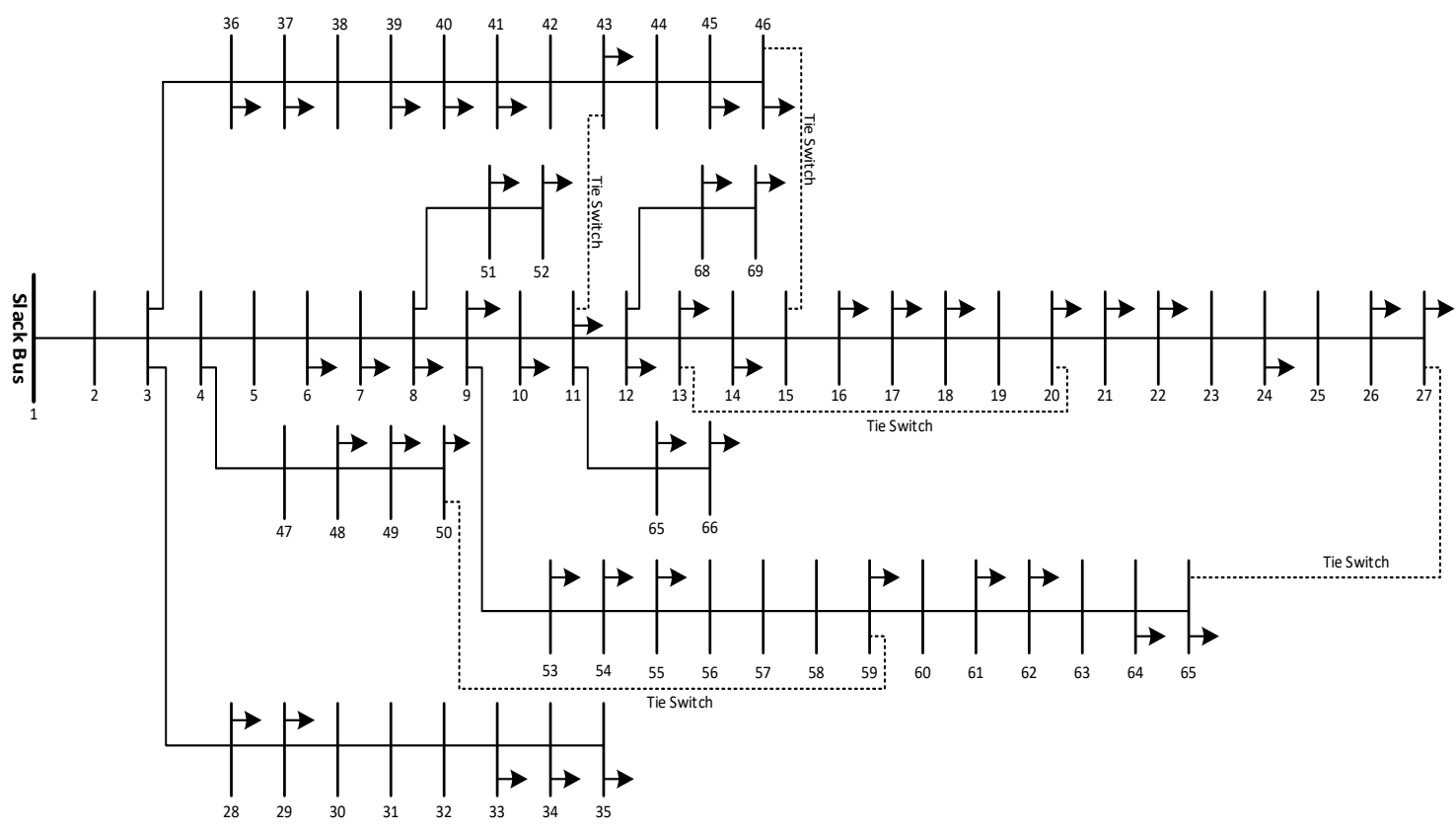

Figure 3. IEEE-69 bus test system

\subsubsection{Study case}

This research conducted a simulation of several study cases to determine the effect of optimization techniques on coordinated planning in finding the objective function. To test the effectiveness of the optimization technique proposed in this study, a simulation of combination of optimization techniques that has been proposed by previous studies is carried out using the PSO method.

1. Scenario $1(\mathrm{~S}-1)$. Normal case

2. Scenario 2 (S-2). Network reconfiguration

3. Scenario 3 (S-3). DG placement

4. Scenario 4 (S-4). Capacitor Placement

5. Scenario 5 (S-5). DG placement and capacitor placement

6. Scenario 6 (S-6). DG placement and network reconfiguration

7. Scenario 7 (S-7). Capacitor placement and network reconfiguration

8. Scenario 8 (S-8). DG placement, capacitor placement and network reconfiguration

\section{RESULTS AND DISCUSSION}

Harmonic current injection on load bus by placing harmonic source will generate harmonics spread on the system. The searching results of the optimization techniques carried out in coordinated planning based on a predetermined scenario use the particle swarm optimization method.

\subsection{IEEE 33-bus test system}

The result of the optimization technique performed is shown in Table 2, Figure 4, Figure 5, and Figure 6. Table 2 shows the simulation results for all scenarios for the IEEE 33-bus test system. The use of PSO Algorithm is able to provide the best solution for the planning carried out. Simulation results for all scenarios vary based on the ability of the optimization techniques used in finding desired solutions that are seen by decreasing the value of fitness. Scenario 8 provides the best solution in this plan that can reduce total active power losses by $67.89 \%$ or $82.85 \mathrm{~kW}$ both in terms of fundamental and each order of harmonic distortion.

Reviewing the spread of harmonic distortion also improved with a decrease in the THDv value (\%) on each bus that does not pass IEEE Standard 519-1992 as shown in Figure 4. Each scenario has its own performance in reducing the spread of harmonic distortion to the use or combination of optimization techniques used. Figure 5 shows that all the techniques used are able to improve the voltage profile better than the baseline condition (Scenario 1) without exceeding the allowable limit so that the voltage deviation value in each load bus decreases as shown in Figure 6. 
Table 2. Result of study case IEEE 33-bus test system

\begin{tabular}{|c|c|c|c|c|c|c|c|c|c|}
\hline \multicolumn{2}{|c|}{ Parameter } & S.1 & S.2 & S.3 & S.4 & S.5 & S.6 & S.7 & S.8 \\
\hline \multicolumn{2}{|c|}{ Fitness } & - & 38.722 & 41.508 & 66.208 & 38,193 & 37.670 & 40.219 & 25.456 \\
\hline \multirow{2}{*}{$\begin{array}{c}\text { DG } \\
(\mathrm{kW})\end{array}$} & Loc & - & - & $\begin{array}{c}7,9,17 \\
31\end{array}$ & - & $\begin{array}{c}13,17,29, \\
31\end{array}$ & $\begin{array}{c}9,12,10 \\
20\end{array}$ & - & $\begin{array}{c}7,16,29, \\
31,\end{array}$ \\
\hline & Sizing & - & - & $\begin{array}{c}200,200, \\
200,200\end{array}$ & - & $\begin{array}{c}200,200 \\
200,200\end{array}$ & $\begin{array}{c}200,200 \\
70.21,200\end{array}$ & - & $\begin{array}{c}200,200, \\
200,200\end{array}$ \\
\hline \multirow{2}{*}{$\begin{array}{c}\text { Cap } \\
\text { (kVar) }\end{array}$} & Loc & - & - & - & $\begin{array}{c}8,15,17 \\
26\end{array}$ & $\begin{array}{c}3,17,25 \\
29\end{array}$ & - & $\begin{array}{c}6,7,14 \\
32\end{array}$ & $\begin{array}{c}5,8,31 \\
33\end{array}$ \\
\hline & Sizing & - & - & - & $\begin{array}{c}50,50 \\
50,50\end{array}$ & $\begin{array}{c}50,50,50, \\
50\end{array}$ & - & $\begin{array}{l}50,50 \\
50,50\end{array}$ & $\begin{array}{l}50,50 \\
50,50\end{array}$ \\
\hline \multicolumn{2}{|c|}{ Active Tie } & - & $8-21$ & - & - & - & $12-22$ & $12-22$ & $8-21$ \\
\hline \multicolumn{2}{|c|}{ Sec Tie Open } & - & $6-7$ & - & - & - & $10-11$ & $8-9$ & $7-8$ \\
\hline \multicolumn{2}{|c|}{$P_{\text {Loss }}(\mathrm{kW})$} & 122.03 & 64.16 & 68.75 & 114.81 & 63.08 & 65.43 & 71.60 & 39.18 \\
\hline \multicolumn{2}{|c|}{$Q_{\text {Loss }}(\mathrm{kVAr})$} & 87.86 & 55.19 & 38.63 & 82.7 & 35.54 & 46.99 & 50.77 & 27.39 \\
\hline \multicolumn{2}{|c|}{ THD max } & 5.116 & 3.368 & 2.568 & $4 . .793$ & 2.161 & 3.363 & 3.632 & 2.636 \\
\hline \multicolumn{2}{|c|}{ THD min } & 0.456 & 0.300 & 0.272 & 0.451 & 0.295 & 0.011 & 0.007 & 0.197 \\
\hline
\end{tabular}

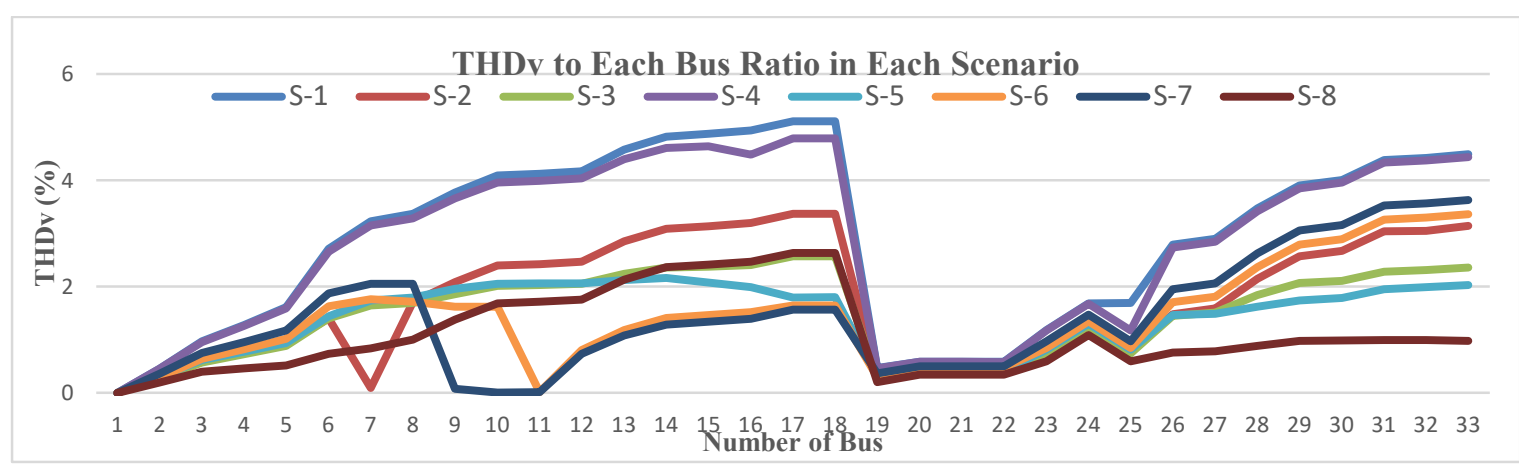

Figure 4. THDv value on each bus for all scenarios for IEEE 33-bus test system

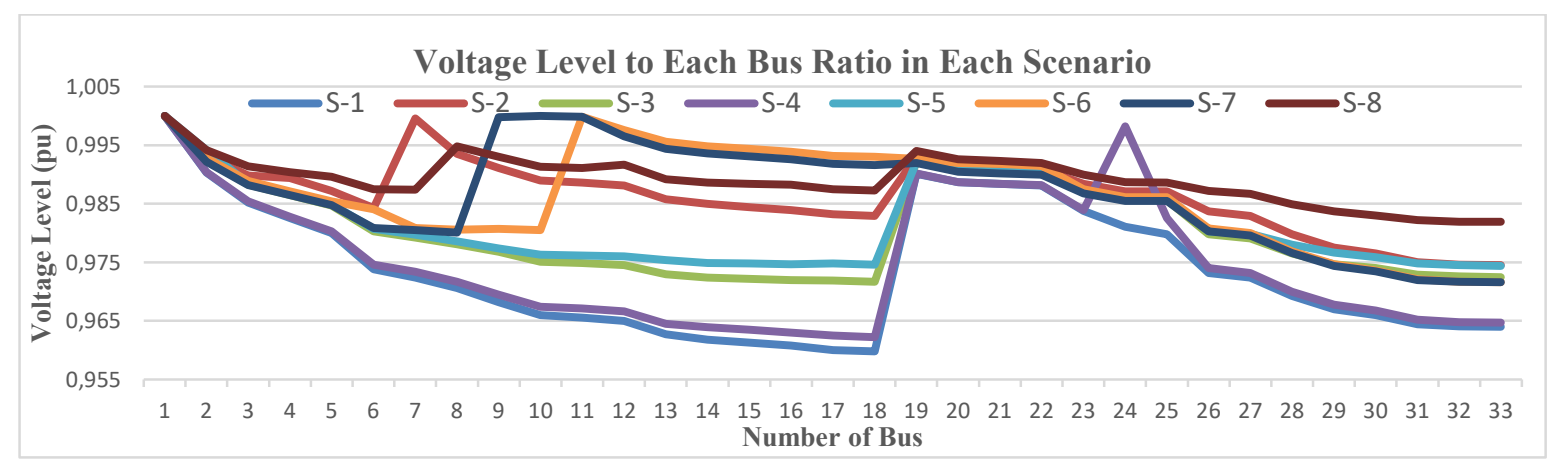

Figure 5. Level of voltage bus on each bus for all scenario for IEEE 33-bus test system

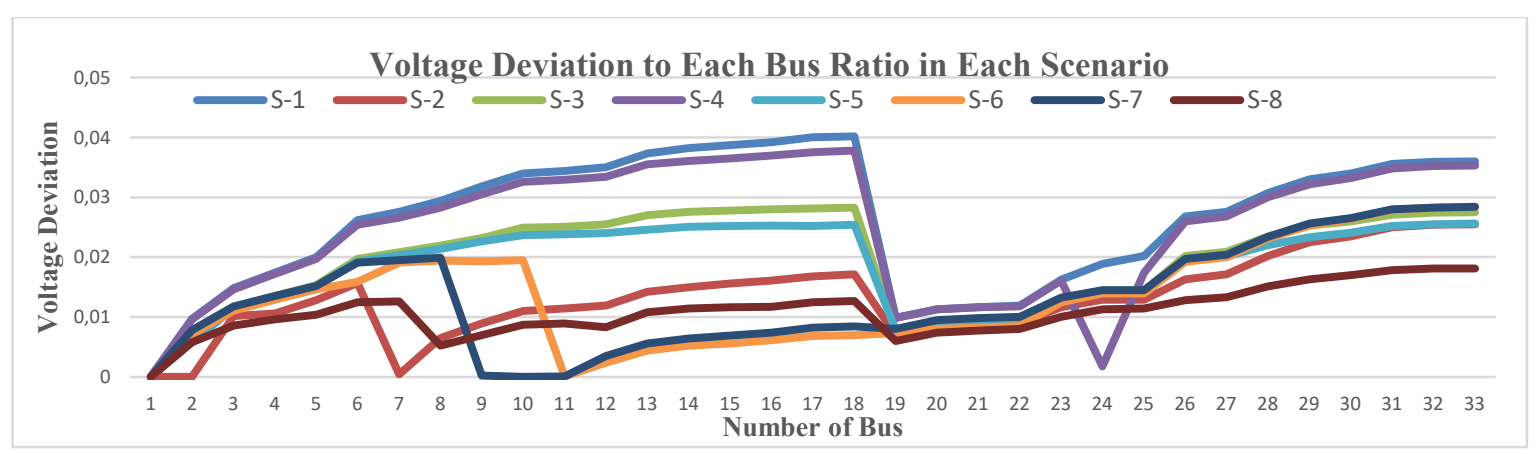

Figure 6. Voltage deviation value on each bus for all scenario for IEEE 33-bus test system

Int J Elec \& Comp Eng, Vol. 11, No. 6, December 2021 : 4610 - 4621 
The use of optimization techniques that are single from the three optimization techniques that provide the best solution is reconfiguration network (S-2). Network reconfiguration is able to change the value of network impedance that can change the electric current flowing and repair voltage levels followed by reduced active power losses. The magnitude of the spread of Harmonic distortion in the system is very dependent on the current flowing on the load and the voltage level on each bus so that the spread of harmonic distortion can be reduced by network reconfiguration techniques as in research [22], [36], [37]. The size of DG placement and capacitor placement resulting in the use of the PSO algorithm are at the maximum limit. Thus, the performance of the system will be better in improving the quality of power with a size of DG $>200 \mathrm{kWatt}$ and capacitors $>50 \mathrm{kVAr}$. The combination of three optimization techniques can simultaneously provide the best performance to improve power quality in reducing the spread of harmonic distortion.

\subsection{IEEE 69-bus test system}

The result of the optimization technique performed is shown in Table 3, Figure 7, Figure 8, and Figure 9. Table 3 shows the simulation results for all scenarios for the IEEE 69-bus test system. In contrast to the IEEE 33-bus test system, with almost the same total load, the IEEE 69-bus test system has a larger number of load buses so that the network impedance is greater that makes the spread of harmonic distortion in the form of THDv exceed the allowable limit of up to $7.673 \%$ on bus 65 . In addition, the reactive power losses value in the 5 th order is $128.41 \mathrm{kVar}$, which is greater than its fundamental value. The use of the PSO method from all existing scenarios can increase power quality where there is a decrease in active power losses by $39.62 \%$ or $107.01 \mathrm{kWatt}$ in scenario 8 and $37.54 \%$ or $101.39 \mathrm{kWatt}$ in scenario 2 .

Table 3. Result of study case IEEE 69-bus test system

\begin{tabular}{|c|c|c|c|c|c|c|c|c|c|}
\hline \multicolumn{2}{|c|}{ Parameter } & S.1 & S.2 & S.3 & S.4 & S.5 & S.6 & S.7 & S.8 \\
\hline \multicolumn{2}{|c|}{ Fitness } & - & 77.5693 & 99.6067 & 113.6014 & 93,2101 & 79.3485 & 83.6948 & 76.1402 \\
\hline \multirow{2}{*}{$\begin{array}{c}\mathrm{DG} \\
(\mathrm{kW})\end{array}$} & Loc & - & - & $\begin{array}{l}23,51 \\
61,63\end{array}$ & - & $\begin{array}{c}27,36,59, \\
65\end{array}$ & $\begin{array}{c}2,20,24 \\
45\end{array}$ & - & $\begin{array}{l}10,11, \\
37,56\end{array}$ \\
\hline & Sizing & - & - & $\begin{array}{l}231,193 \\
241,214\end{array}$ & - & $\begin{array}{c}192,95 \\
219,232\end{array}$ & $\begin{array}{l}163,157 \\
190,122\end{array}$ & - & $\begin{array}{l}29,120 \\
170,87\end{array}$ \\
\hline \multirow{2}{*}{$\begin{array}{c}\text { Cap } \\
\text { (kVar) }\end{array}$} & Loc & - & - & , & $\begin{array}{l}14,17 \\
21,27\end{array}$ & $\begin{array}{c}9,32,36 \\
65\end{array}$ & - & $\begin{array}{c}5,43,50 \\
66\end{array}$ & $\begin{array}{c}29,47 \\
60,69\end{array}$ \\
\hline & Sizing & - & - & - & $\begin{array}{l}65,62, \\
93,77\end{array}$ & $\begin{array}{c}47,26,87, \\
81\end{array}$ & - & $\begin{array}{l}60,25 \\
76,38\end{array}$ & $\begin{array}{c}6,71,6 \\
91\end{array}$ \\
\hline \multicolumn{2}{|c|}{ Active Tie } & - & $50-59$ & - & - & - & $11-43$ & $11-43$ & $50-59$ \\
\hline \multicolumn{2}{|c|}{ Sec Tie Open } & - & $58-59$ & - & - & - & $8-9$ & $8-9$ & $55-56$ \\
\hline \multicolumn{2}{|c|}{$P_{\text {Loss }}(\mathrm{kW})$} & 270.05 & 168.66 & 208.30 & 255.16 & 214.59 & 192.32 & 202.46 & 163.04 \\
\hline \multicolumn{2}{|c|}{$Q_{\text {Loss }}(\mathrm{kVAr})$} & 248.32 & 258.26 & 199.41 & 235.79 & 212.59 & 177.75 & 180.85 & 251.21 \\
\hline \multicolumn{2}{|c|}{ THD max } & 7.673 & 7.663 & 6.827 & 7.561 & 7.384 & 6.414 & 6.372 & 7.539 \\
\hline \multicolumn{2}{|c|}{ THD min } & 0.006 & 0.006 & 0.005 & 0.006 & 0.005 & 0.001 & 0.001 & 0.005 \\
\hline
\end{tabular}

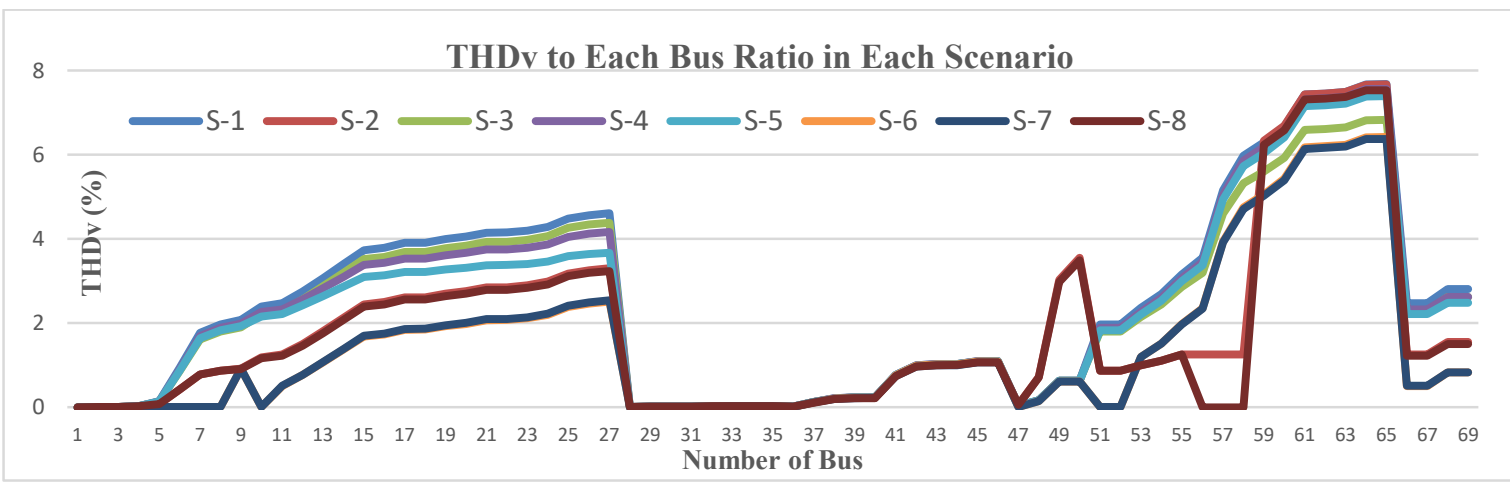

Figure 7. THDv value on each bus for all scenarios for IEEE 69-bus test system

The reduction in the spread of harmonic distortion occurs in every scenario that is shown in Figure 7 but still exceeds the allowed limit. The improvement of the voltage level on each bus and the reduced voltage deviation that is shown in Figure 8 and Figure 9. The use of optimization techniques, both single and plural, has been said to improve the performance of the system in terms of improving the quality of power against the spread of harmonic distortion but not yet maximized. 


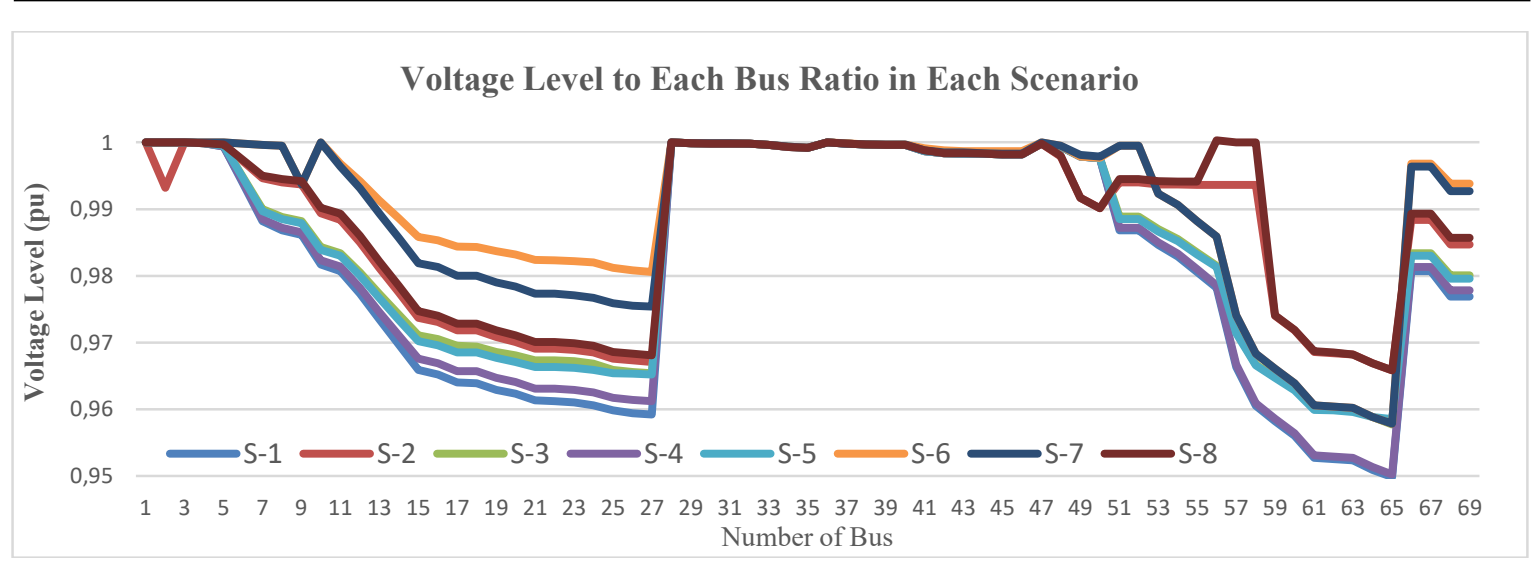

Figure 8. Level of voltage bus on each bus for all scenario for IEEE 69-bus test system

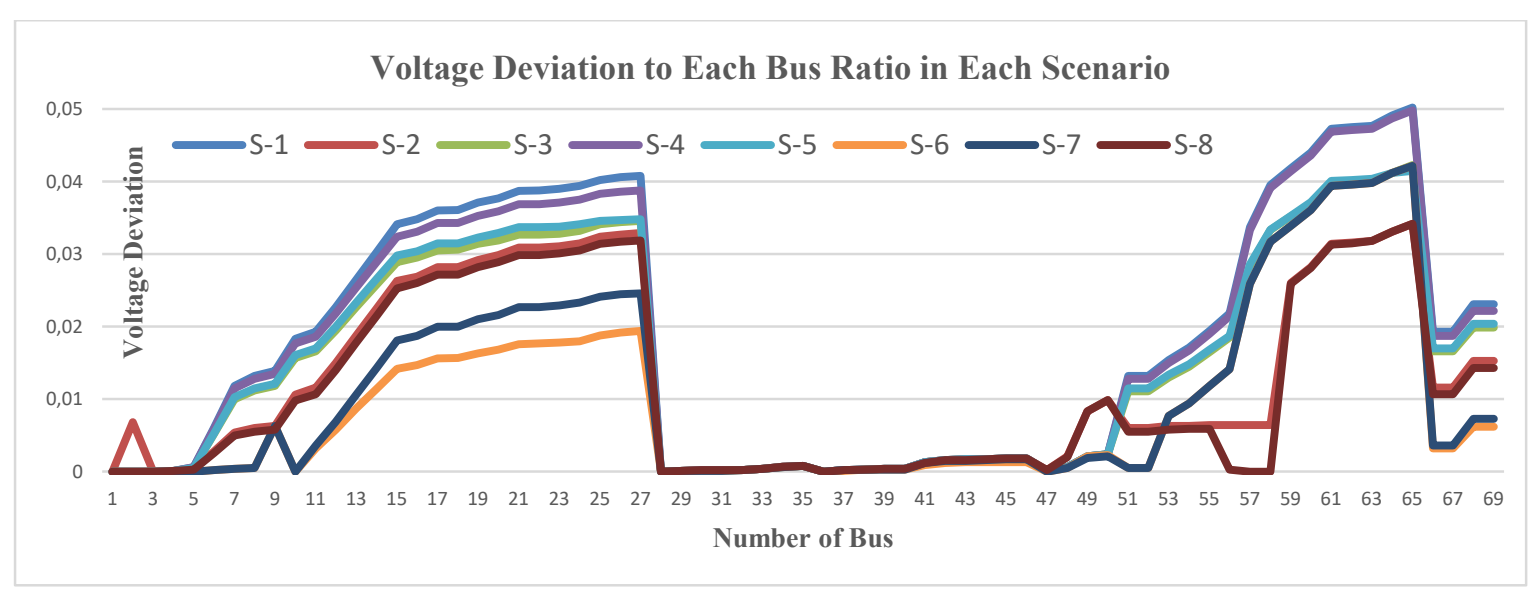

Figure 9. Voltage deviation value on each bus for all scenario for IEEE 69-bus test system

\section{CONCLUSION}

In this paper, the use of the PSO algorithm is able to provide solutions to all scenarios carried out in finding the objective function in increasing power quality to the spread of harmonics. The simulation results verify that the effectiveness of the proposed method and also the solution to all scenarios carried out. Planning that gives maximum result is in scenario 8 in the form of a combination of three simultaneous optimization techniques between DG placement, capacitor placement and network reconfiguration of the two objects used. Taking into account harmonic distortion resulting from the use of non-linear loads in the radial distribution system as a multi-objective function provides the appropriate criteria in carrying out this planning. Further planning is needed regarding the handling of harmonics distribution in a larger distribution system and real distribution systems in Indonesia which will be discussed in the next paper with other method.

\section{ACKNOWLEDGEMENTS}

Thank you very much for my lovely mother and father for their encouragement and financial support to my doctoral study at ITS-Surabaya and Doctoral Dissertation Research Fund (Hibah-PDD) from Ministry of Higher Education, and thank you to my big family on Department of Mechatronic Engineering, Polytechnic of Bosowa, Thank you very much.

\section{REFERENCES}

[1] P. Bagheri, W. Xu, and T. Ding, "A Distributed Filtering Scheme to Mitigate Harmonic in Residential Distribution System," IEEE Transactions Power Delivery, vol. 31, no. 2, pp. 648-656, 2016, doi: 10.1109/TPWRD.2015.2460460. 
[2] M. Mohammadi, "Bacterial Foraging Optimization and Adaptive Version for Economically Optimum Sitting, Sizing and Harmonic Tuning Orders Setting of LC Harmonic Passive Filters in Radial Distribution System with Linear and Nonlinear Loads," Elsevier Applied Soft Computing, vol. 29, pp. 345-356, 2015, doi: 10.1016/j.asoc.2015.01.021.

[3] M. D. Faraby and O. Penangsang, "A Study of Harmonic Spreading against Distribution Network Reconfiguration in Passive Radial Distribution Systems," $4^{\text {th }}$ International Conference Science and Technology, Yogyakarta, Indonesia, 2018, doi: 10.1109/ICSTC.2018.8528665.

[4] Y. Wang, J. Yong, Y. Sun, W. Xu, and D. Wong, "Characteristic of Harmonic Distortion in Residential Distribution System," IEEE Transaction on Power Delivery, vol. 32, pp. 1495-1504, 2017, doi: 10.1109/TPWRD.2016.2606431.

[5] A. Denyal, O. Penangsang, and D. A. Asfani, "Radial Distribution System Modeling for Three Phase Harmonic Power Flow Studies," (in Indonesia), Jurnal Teknik POMITS, vol. 2, no. 2, pp. B-128-B130, 2013.

[6] M. D. Faraby, A. Fitriati, Christiono, Usman, A. Muchtar, and A. N. Putri, "Single Tuned Filter to Mitigate Harmonic Polluted in Radial Distribution Network Using Particle Swarm Optimization," International Seminar on Research of Information Technology and Intelligent System, 2020, pp. 418-422, doi: 10.1109/ISRITI51436.2020.9315518.

[7] U. Ghatak, V. Mukherjee, A. Y. Abdelaziz, S. H. E. A. Aleem, and H. M. A. Mageed, "Time-Efficient Load Flow Technique for Radial Distribution Systems with Voltage-Dependent Loads," International Journal on Energy Conversion, vol. 6, no. 6, pp. 196-207, 2018, doi: 10.15866/irecon.v6i6.15765.

[8] A. Arunagiri and B. Venkatesh, "Harmonic Load Flow for Radial Distribution Systems," Journal of Engineering Science and Technology, vol. 6, no. 3, pp. 300-310, 2011.

[9] J. H. Teng and C. Y. Chang, "Backward/Forward-Based Harmonic Analysis Method for Distribution System," IEEE Transaction on Power Delivery, vol. 22, no. 3, pp. 1665-1672, 2007, doi: 10.1109/TPWRD.2007.899523.

[10] M. D. Faraby and O. Penangsang, "Impact Optimal DG Placement against Harmonic Distribution on Reconfiguration Distribution Network on Microgrid System," IOP Conference Series: Material Science and Engineering, vol. 676, 2018, doi: 10.1088/1757-899X/676/1/012007.

[11] Suyanto, C. Rahmadhani, O. Penangsang, and A. Soeprijanto, "Power-Flow Development Based on the Modified Backward Forward for Voltage Profile Improvement of Distribution System," International Journal of Electrical and Computer Engineering (IJECE), vol. 6, no. 5, pp. 2005-2014, 2016, doi: 10.11591/ijece.v6i5.pp2005-2014.

[12] R. Shayani and M. D. Oliveira, "Photovoltaic Generation Penetration Limit in Radial Distribution System," IEEE Transaction Power System, vol. 26, no. 3, pp. 619-624, 2011, doi: 10.1109/TPWRS.2010.2077656.

[13] Umar, Firdaus, M. Ashari, and O. Penangsang, "Optimal Location, Size and Type of DGs to Reduce Power Losses and Voltage Deviation Considering THD in Radial Unbalanced Distribution System," 2016 International Seminar on Intelligent Technology and Its Applications (ISITIA), Lombok, 2016, pp. 577-582, doi: 10.1109/ISITIA.2016.7828724.

[14] A. Bhowmik, A. Maitra, S. M. Halpin, and J. E. Schatz, "Determination of Allowable Penetration Level of Distributed Energy Generation Resources Based on Harmonic Limit Considerations," IEEE Transaction Power Delivery, vol. 18, no. 2, pp. 619-624, 2013, doi: 10.1109/TPWRD.2003.810494.

[15] Y. A. Rahman, S. Manjang, Yuran, and A. A. Ilham, "An Empirical Metaheuristic Assessment for Solving of Multi-Type Distributed Generation Allocation Problem," International Seminar on Research of Information Technology and Intelligent System, pp. 699-702, 2018, doi: 10.1109/ISRITI.2018.8864438.

[16] Y. A. Rahman, S. Manjang, Yuran, and A. A. Ilham, "Selection of Sensitive Buses using the Firefly Algorithm for Optimal Multiple Types of Distributed Generations Allocation," International Journal of Advanced Computer Science and Applications, vol. 10, no. 10, pp. 316-322, 2019, doi: 10.14569/ijacsa.2019.0101045.

[17] S. S. Rangarajan, E. R. Collins, and C. Fox, "Efficacy of Smart Photovoltaic Inverter as a Virtual Detuner for Mitigating Network Harmonic Resonance in Distribution Systems," Electric Power Systems Research, vol. 171, pp. 175-184, 2019, doi: 10.1016/J.EPSR.2019.02.001.

[18] S. Sekar, M. E. Balci, S. H. E. A. Aleem, and A. F. Zooba, "Increasing PV Hosting Capacity in Distorted Distribution System Using Passive Harmonic Filtering," Electric Power System Research, vol. 148, pp. 74-86, 2017, doi: 10.1016/J.EPSR.2017.03.020.

[19] R. Shah, M. Muthulanantan, R. C. Bansal, and V. K. Ramachandaramurthy, "A Review of Key Power System Stability Challenges for Large-Scale PV Integration," Renewable and Sustainable Energy Reviews, vol. 41, pp. 1423-1436, 2015, doi: 10.1016/j.rser.2014.09.027.

[20] M. S. S. Azevedo, I. P. Abril, J. C. Leite, A. B. De Medeiros, "Capacitor Placement by NSGA-II in Distribution System with Non-Linear Loads," International Journal of Electrical Power and Energy Systems, vol. 82, pp. 281-287, 2016, doi: 10.1016/j.ijepes.2016.03.025.

[21] J. Vuletic and M. Todoroyski, "Optimal Capacitor Placement in Distorted Distribution Network with Different Load Model Using Penalty Free Genetic Algorithm," International Journal of Electric Power and Energy System, vol. 78, pp. 174-182, 2016, doi: 10.1016/j.ijepes.2015.11.065.

[22] Yaidah Ch, S. K. Goswami, and D. Chatterjee, "Effect of Network Reconfiguration on Power Quality of Distribution System," International Journal of Electric Power and Energy System, vol. 83, pp. 87-95, 2016, doi: 10.1016/j.ijepes.2016.03.043.

[23] E. K. Robati and M. S. Sepasian., "Fast Heuristic Method for Harmonic Minimization Using Distribution System Reconfiguration,” Electric Power System Research, vol. 181, pp. 1-11, 2020, doi: 10.1016/j.epsr.2019.106185. 
[24] A. Marini, M. S. Ghazizadeh, S. S. Mortazavi, and L. Piegari, "A Harmonic Power Market Framework for compensation management of DERs Based Active Power Filters in Microgrids," International Journal of Electric Power and Energy Systems, vol. 113, pp. 916-931, 2019, doi: 10.1016/j.ijepes.2019.06.020.

[25] M. A. Amini, A. Jalilia, and M. R. P. Behbahani, "Fast Network Reconfiguration in Harmonic Polluted Distribution Network Based on Developed Backward/Forward Sweep Harmonic Load Flow," Electric Power System Research, vol. 168, pp. 295-304, 2019, doi: 10.1016/j.epsr.2018.12.006.

[26] F. Sayadi, S. Esmaeili, and F. Keynia, "Feeder Reconfiguration and Capacitor allocation in the Presence of NonLinear Loads Using New-PSO Algorithm," IET Generation, Transmission \& Distribution, vol. 10, pp. 2316-2326, 2016, doi: 10.1049/iet-gtd.2015.0936.

[27] S. Biswas, S. K. Goswami, and A. Chatterjee, "Optimal Distributed Generation Placement in Shunt Capacitor Compensated Distribution System Considering Voltage Sag and Harmonic Distortion," IET Generation, Transmission and Distribution, vol. 8, pp. 783-797, 2014, doi: 10.1049/IET-GTD.2013.0423.

[28] M. Kumawat, N. Gupta, N. Jain, and R. C. Bansal, "Optimal Planning of Distributed Energy Resources in Harmonic Polluted Distribution System," Swarm and Evolutionary Computation, vol. 39, pp. 99-113, 2018, doi: 10.1016/j.swevo.2017.09.005.

[29] M. D. Faraby, A. Fitriati, Christono, Usman, A. Muchtar, and A. N. Putri, "Single Tuned Filter Planning to Mitigate Harmonic Polluted in Radial Network Using Particle Swarm Optimization," $3^{\text {rd }}$ International Seminar on Research of Information Technology and Intelligent Systems, 2020, pp. 418-422, doi: 10.1109/ISRITI51436.2020.9315518.

[30] M. D. Faraby, O. Penangsang, R. S. Wibowo, and A. Sonita, "Improved Performance Network Reconfiguration in Coordinated Planning in Radial Distribution System Considering Harmonic Distortion," International Review on Modelling and Simulations (IREMOS), vol. 14, no. 2, 2021, doi: 10.15866/iremos.v14i2.20472.

[31] E. P. Santoso, O. Penangsang, and N. K. Aryani, "Optimization of Determination Location of Capacitor and Distributed Generation (DG) with network reconfiguration to Increase Output Active Power of DG in Radial Distribution System Using Genetic Algorithm (GA)," (in Indonesia), Jurnal Teknik ITS, vol. 5, no. 2, pp. 160-166, 2016, doi: 10.12962/j23373539.v5i2.16244.

[32] Suyanto, "Decision Support System (DSS) CP based Advanced OPF HCT: Radial Distribution System Network Planning, Operating and Optimization Simulator," (in Indonesia), Dissertation, Institute Technology of Sepuluh Nopember, Surabaya, Indonesia, 2018. [Online]. Available: https://repository.its.ac.id/id/eprint/51397.

[33] F. Haz, G. A. Setia, Yusran, S. M. Said, and H. R. Iskandar, "The Optimization of SVC Placement in Sulselbar Transmission System Using Inertia Weight Particle Swarm Optimization," $2^{\text {nd }}$ International Conference on High Voltage Engineering and Power Systems, 2019, doi: 10.1109/ICHVEPS47643.2019.9011127.

[34] J. Kennedy and R. Eberhard., "Particle Swarm Optimization," International Conference Neural Network, Piscataway, NJ, 1995, pp. 1942-1948, doi: 10.1109/ICNN.1995.488968.

[35] A. Rosyadi, O. Penangsang, and A. Soeprijanto, "Optimal Filter Placement and Sizing in Radial Distribution System Using Whale Optimization Algorithm," International Seminar on Intelligent Technology and Its Application, Surabaya, Indonesia, 2017, pp. 87-92, doi: 10.1109/ISITIA.2017.8124060.

[36] S. Jazebi and B. Vahidi, "Reconfiguration of Distribution Network to Mitigate Utilities Power Quality Disturbances," Electric Power System Research, vol. 91, pp. 9-17, 2012, doi: 10.1016/j.epsr.2012.04.008.

[37] S. Jazebi, M. M. Hadji, and R. A. Naghizadeh, "Distribution Network Reconfiguration in the Presence of Harmonic Load: Optimization Techniques and Analysis," IEEE Transaction on Smart Grid, vol. 5, no. 4, pp. 1929-1937, 2014, doi: 10.1109/TSG.2014.2314124.

\section{BIOGRAPHIES OF AUTHORS}

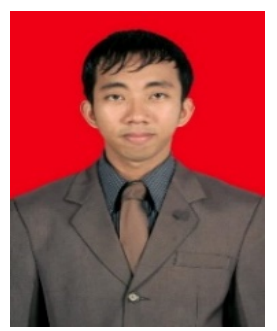

Muhira Dzar Faraby received the S.T degree in 2012 and M.T degree in 2014 from department of Electrical Engineering, Hasanuddin University, Indonesia. Currently he is a doctoral student of Electrical Engineering, Institute Technology of Sepuluh Nopember (ITS), Surabaya, Indonesia. His research interest includes power quality, power system optimization, power electronics, artificial intelligence, and renewable energy resources.

Email : muhira16@mhs.ee.its.ac.id

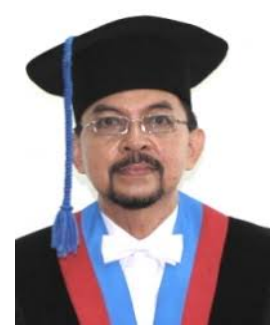

Ontoseno Penangsang received the Ir. degree in 1974 from the department of Electrical Engineering ITS-Surabaya, Indonesia, the M.Sc. in 1976 and Ph.D. degree in 1983 from the department of Electrical Engineering, University of Wisconsin-Madison, USA. Currently, he is a lecturer and professor in Electrical Engineering, ITS-Surabaya, Indonesia. His research interest includes GIS for Power System, power quality, power distribution system, power system optimization, and renewable energy resources.

Email : zenno_379@yahoo.com 


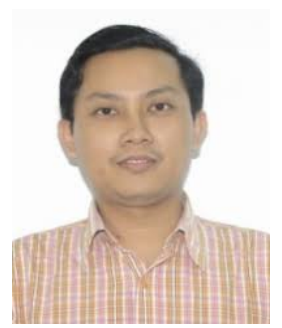

Rony Seto Wibowo received the S.T degree in 1999 from the department of Electrical Engineering ITS-Surabaya Indonesia, the M.T degree in 2006 at ITB-Bandung Indonesia and the D.Eng. degree in 2011 from Electrical Engineering of Hiroshima University, Japan. Currently, he is a lecturer and head of Power System Simulation Laboratory of Electrical Engineering, ITSSurabaya, Indonesia. His research interest includes stability power system, power quality, FACTS Devices, and renewable energy resources.

Email : ronyseto@ee.its.ac.id

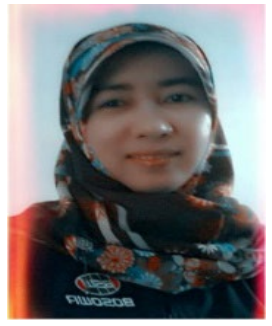

Andi Fitriati received the S.T degree in 2004 from the department of Electrical Engineering and the M.T degree in 2012 from Informatic Engineering, Hasanuddin University, Indonesia. Currently, she is a lecturer of Mechatronic Engineering, Polytechnic of Bosowa, Indonesia. Her research interest includes artificial intelligence, big data, machine learning, and digital system. Email : andi.fitriati@bosowa.co.id 